\title{
Sophie Nizard, Adopter et transmettre. Filiations adoptives dans le judaïsme contemporain
}

Paris, Éditions de l'EHESS, coll. « En temps et en lieux », 2012, 240 p.

Florence Heymann

\section{OpenEdition}

\section{Journals}

Édition électronique

URL : http://journals.openedition.org/assr/24667

DOI : $10.4000 /$ assr.24667

ISSN : $1777-5825$

Éditeur

Éditions de l'EHESS

Édition imprimée

Date de publication : 30 décembre 2012

Pagination : 244

ISSN : 0335-5985

Référence électronique

Florence Heymann, « Sophie Nizard, Adopter et transmettre. Filiations adoptives dans le judaïsme contemporain », Archives de sciences sociales des religions [En ligne], 160 | octobre-décembre 2012, mis en ligne le 21 mars 2013, consulté le 21 septembre 2020. URL : http://journals.openedition.org/assr/ 24667 ; DOI : https://doi.org/10.4000/assr.24667

Ce document a été généré automatiquement le 21 septembre 2020.

(c) Archives de sciences sociales des religions 
Sophie Nizard, Adopter et transmettre. Filiations adoptives dans le judaïsme contemporain

Paris, Éditions de l'EHESS, coll. « En temps et en lieux », 2012, 240 p.

Florence Heymann

\section{RÉFÉRENCE}

Sophie Nizard, Adopter et transmettre. Filiations adoptives dans le judaïsme contemporain, Paris, Éditions de l'EHESS, coll. « En temps et en lieux », 2012, 240 p. 
1 L'ouvrage, résultat d'une recherche sur l'adoption en milieu juif, s'inscrit dans une sociologie du judaïsme, au croisement des problématiques de la transmission familiale, de la mémoire et de la religion (p.17). Il ouvre à une réflexion sur les identités et les mémoires collectives, et sur la manière dont se construit une famille, au-delà du biologique. La conversion et l'adoption sont deux processus impliquant un changement fondamental du statut de l'individu, cette dernière impliquant notamment un changement de filiation. L'émergence de nouvelles formes familiales, qui a notamment conduit à un effondrement $\mathrm{du}$ modèle de la famille bioconjugale en tant que norme, donne aux familles adoptives des exemples de parentalité déconnectée

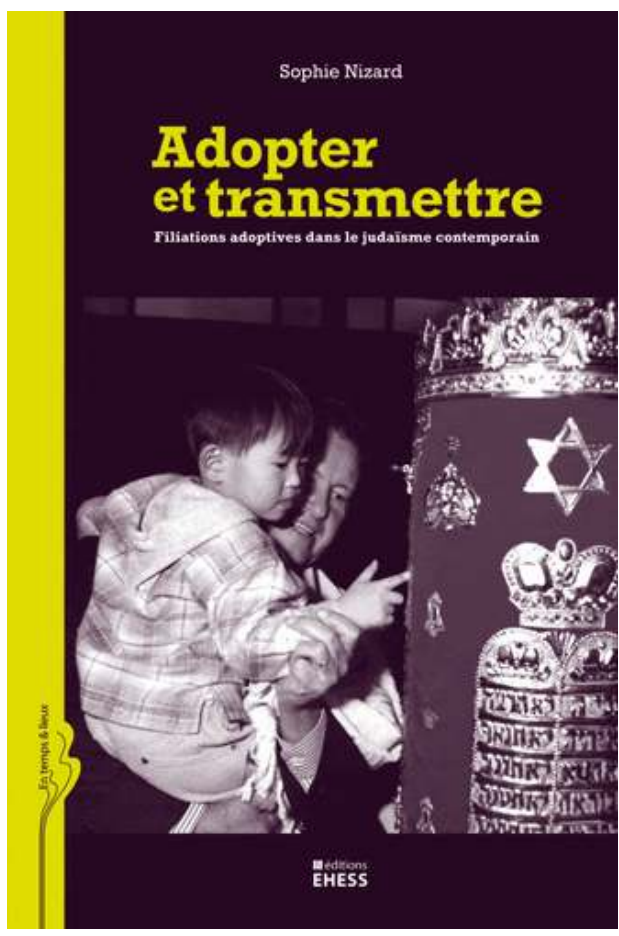
$\mathrm{du}$ biologique. Elle renforce ainsi leur représentation de la parenté adoptive qu'ils vivent alors telle une parenté comme une autre (p. 133).

Le chapitre premier traite de la filiation dans les textes et positions halakhiques contemporaines. Alors que l'impératif de croître et de multiplier est le premier commandement de la Bible, le même texte nous parle des nombreux cas de stérilité des matriarches. Alors que l'on trouve un texte relatif à la conversion, avec Ruth la Moabite, dans la Bible, aucun texte ne réfère directement à l'adoption. Dans le Talmud en revanche, de nombreux textes reconnaissent des modes de filiation non fondés sur le biologique, affirmant qu'élever un orphelin, le nourrir, lui enseigner la Torah, c'est « comme si » on l'avait enfanté.

3 La halakha, la loi religieuse juive en tant que productrice de normes, ne peut éviter la réflexion sur les nouvelles formes de parentalité, comme l'adoption. L'auteur souligne par ailleurs la diversité des approches contemporaines quant au statut religieux de l'enfant adopté.

4 Le chapitre suivant décrit les terrains de la recherche en France et en Israël, qu'il s'agisse d'adoption nationale ou internationale. L'une des différences fondamentales entre les deux terrains réside dans deux éléments fondamentaux : premièrement, la France est un pays laïque où le critère religieux n'entre guère en ligne de compte. En Israël, le «statu quo » fait qu'au niveau de l'état-civil, il n'y a pas de séparation de la religion et de l'État; et, là où les Juifs forment une minorité en France, ils sont la majorité en Israël. Toutefois, en dépit des grandes différences, dans les deux pays, les institutions tentent d'anticiper les problèmes que parents et enfants risquent de rencontrer: manque d'identification réciproque, réaction face au racisme de l'entourage, transposition de problèmes politiques ou de conflits interethniques au sein de la famille (p. 69).

5 Le chapitre III retrace le «parcours du combattant» des candidats à l'adoption. Il analyse le désir d'enfants et la douleur de l'infertilité. De fait, l'adoption apparaît moins 
souvent comme une évidence que comme un dernier recours. Elle implique notamment de devoir faire le "deuil de l'enfant biologique ", expression paradoxale s'il en est, parlant d'un être qui n'est pas né. L'objet de l'enquête montre également qu'aux habituelles tracasseries administratives s'ajoutent, dans une large mesure, celle d'un autre « parcours du combattant ", peut-être encore plus drastique que le premier, celui de la conversion de l'enfant au judaïsme et des refus souvent occasionnés par la moindre orthodoxie ou son absence des parents, fermant souvent la porte au processus d'une conversion consistoriale.

6 La rencontre entre parents et enfant apparaît comme le temps fort de l'adoption, tout particulièrement chargé émotionnellement. Les récits en portent tous témoignage. Puis vient le temps, à travers le vécu quotidien, de la construction de la parenté et de son inscription dans une généalogie, à travers les actes hautement symboliques que sont la dation du nom, la circoncision pour les garçons et la conversion au judaïsme. Un des problèmes les plus aigus concernant le judaïsme est celui de la transmission dans le cas de familles assimilées, laïques ou non juives « halakhiquement » et de la confrontation avec une conversion orthodoxe consistoriale - la seule reconnue officiellement notamment en Israël.

7 Enfin, l'ouvrage donne également la parole à des adoptés confrontés à la recherche de leurs origines et notamment à ce qui a permis l'adoption, à savoir l'abandon, souvent encore vécu comme acte impensable. La parenté étant construite par affiliations successives à des groupes familiaux différents, et l'adoption se construisant précisément par des liens non biologiques, la recherche des origines tend, elle, à réactiver les liens du sang. Rechercher ses origines, c'est reconstruire, sur la base des liens du sang et d'un passé occulté, une nouvelle parenté originelle qui vient s'ajouter, sans s'y substituer, à la parenté adoptive.

8 L'ouvrage, très documenté et complet, permet d'éclairer les recherches de socioanthropologie du judaïsme, un champ encore relativement pionnier en France. Il me semble toutefois que le corpus israélien est moins systématiquement traité que les récits français, alors même que ce sujet est aujourd'hui l'un des dossiers brûlants qui agitent le monde religieux en Israël. 